\title{
Reforma Regulatória Brasileira dos Anos 90 à Luz do Modelo de Kleber Nascimento
}

\begin{abstract}
Alketa Peci
RESUMO

O principal objetivo deste artigo é analisar a reforma regulatória da última década, à luz de outras reformas historicamente implementadas no Brasil. Para isso, inicialmente, é apresentada uma breve trajetória do processo de criação das agências reguladoras e discutido o papel regulatório do Estado. Em seguida, é analisado o marco regulatório, destacando-se as vulnerabilidades deste último e diferenciando dois movimentos principais: a política regulatória e as medidas de flexibilização da gestão pública. Visando inserir a análise da reforma regulatória numa perspectiva histórica, é revisitado um modelo clássico de análise das reformas no país, apresentado por Kleber Nascimento. Será observado até que ponto a reforma regulatória se distancia de outros esforços reformistas implementados no país. Entre as principais conclusões do artigo, destaca-se a relevância da discussão acerca do novo papel do Estado na atividade regulatória, escapando aos limites formais da reforma, traduzidos em medidas relativas ao modelo agência independente, que predomina até o momento.
\end{abstract}

Palavras-chave: reforma; regulação; agências reguladoras; Nova Gestão Pública.

\begin{abstract}
The main objective of this paper is to analyze the regulatory reform in the 1990's, based on a comparative perspective regarding other reforms historically implemented in Brazil. Initially, a brief trajectory of the process of creation of regulatory bodies is presented and the regulatory role of the State is discussed. Follows the analysis of regulatory apparatus, highlighting its vulnerabilities and differentiating two principal movements: the regulatory policy and the measures regarding public administration flexibility. In order to analyze the regulatory reform from a historical perspective, a classical model of analysis of public administration reforms, elaborated by Kleber Nascimento, is revisited. The differences between the regulatory reform and other reforms implemented in Brazil would be the principal question of investigation. The relevance of discussion about the new role of State in terms of regulation, furthering the formal boundaries of the reform which implies measures regarding the independent agency model - is highlighted as one of the main conclusions of this paper.
\end{abstract}

Key words: reform; regulation; regulatory bodies; New Public Management. 


\section{INTRODUÇÃO}

O objetivo principal deste artigo é analisar a reforma regulatória implementada no Brasil da pós-privatização. A instituição de agências reguladoras é vista no quadro de uma importante mudança estrutural, na qual a desestatização e a flexibilização da gestão pública são apontadas como componentes principais.

A primeira parte do artigo apresenta breve histórico do processo de implementação das agências reguladoras - destacando aspectos como a desestatização e sua relevância na criação de novos órgãos reguladores - , do processo de estabelecimento das agências e trata do papel do Plano Diretor da Reforma do Aparelho de Estado. Além disso, aborda as premissas teóricas (ou pré-requisitos) nas quais se baseou o modelo agência, bem como discute a abrangência da reforma regulatória nos níveis setorial e federal.

Em seguida, é analisado o marco regulatório implementado e se destacam as principais vulnerabilidades do modelo, com uma reflexão sobre as duas dimensões cruciais: a política regulatória e a tentativa de flexibilização da gestão pública. Paralelamente, no quadro de medidas de flexibilização da gestão pública, os aspectos formais do modelo agência independente tornaram-se o maior foco de preocupação, levando a um considerável grau de isomorfismo organizacional.

A quarta parte do artigo visa analisar a reforma regulatória de uma perspectiva histórica. Para aprofundar essa análise e à luz de outros esforços reformistas implementados historicamente no Brasil, é revisitado o modelo conceitual proposto por Nascimento (1967) em artigo considerado um clássico da Revista de Administração Pública. O autor abstrai um modelo teórico da estratégia de mudança que tem presidido a experiência reformista brasileira. A proposta é procurar observar até que ponto a reforma regulatória se distancia de outros esforços de reforma implementados no Brasil.

Por fim, as principais conclusões deste artigo são apresentadas, ressaltando-se a importância de um aprofundamento da discussão sobre o papel regulatório do Estado brasileiro. Embora carregado de posições ideológicas contraditórias, o debate acerca desse papel, de suas premissas, de sua função e de sua relevância é importante para que as reformas regulatórias não se concentrem apenas nos seus aspectos formais, materializados no modelo agência independente. 


\section{Regulação e Agências Reguladoras: Breve Histórico}

Regulação é intervenção, é restrição pelo poder público da escolha baseada em interesses particulares. No stricto sensu, regulação tem a ver com o estabelecimento de regras de jogo, sendo assim uma função do Estado (Castor, 2000; Marques Neto, 2003).

De fato, a retomada do discurso em torno da regulação tem suas raízes num dos principais vértices do processo de reforma do Estado: a desestatização. De acordo com Abranches (1999), com o processo de desestatização, a economia brasileira deixou de ser uma economia mista, tornando-se uma economia privada de mercado, cujo eixo dinâmico do padrão de produção e acumulação foi definitivamente transferido para o setor privado. O setor de infra-estrutura foi responsável por um terço do arrecadado com a privatização - US $\$ 23,7$ bilhões conseguidos com a venda de 30 empresas estatais (Pires, 1999).

Todavia, a criação das agências reguladoras não resultou de uma discussão quanto ao modelo de regulação. O primeiro passo foi o encaminhamento das leis e, depois, a discussão sobre os conceitos básicos do modelo. As reformas não foram baseadas num amplo consenso na sociedade civil, conforme indicavam as experiências de outros países (Fachin, 1998; Fadul, 1998; Fischer, Teixeira, \& Heber, 1998; Peci, 2002).

A primeira referência às agências reguladoras foi feita pelo Plano Diretor da Reforma do Aparelho de Estado, idealizado pelo Ministério de Administração e Reforma do Estado (antigo Mare). O documento apresentava estratégias que visavam enfrentar os principais obstáculos à implementação de um aparelho de Estado moderno e eficiente. Baseado no diagnóstico de que existia uma crise do Estado - manifestada em seus aspectos fiscais, patrimoniais e gerenciais -, o plano questionava o próprio papel do Estado nesse contexto de crise e propunha um conjunto de medidas de cunho administrativo-gerencial, levando em conta a premissa de que as instituições públicas devem tornar-se mais "parecidas" com o mercado - considerado um ótimo alocador de recursos - o que, na prática, restringia o escopo de atuação do Estado (Martins, 2004).

Uma das principais proposições do modelo regulatório instituído no Brasil é a da eqüidistância do órgão regulador em relação aos pólos de interesse de regulação: o poder concedente (governo), concessionárias e usuários de serviços públicos. Para lidar com essa questão, as agências reguladoras estão instituídas com base num modelo em que são colocadas no centro de um triângulo isósceles - com o governo num dos vértices e operados (empresas reguladas) e usuários nos outros 
dois vértices -, tentando-se obter uma eqüidistância entre o órgão regulador e esses agentes (Fachin, 1998). A existência de controle social é vista como um pré-requisito para o bom andamento do modelo regulatório, de certa forma igualando o poder e a capacidade de articulação e pressão que o governo, empresas reguladas e usuários apresentam.

O modelo agência reguladora retoma os pressupostos de William Willougby e de Woodrow Wilson. Enquanto o primeiro propunha uma distinção clara, estruturalmente definida, entre as atividades-fim e as atividades-meio, Wilson propunha a clara distinção entre política e administração (Wahrlich, 1984). Caberia à técnica (agência reguladora), executar as orientações políticas formuladas no âmbito do núcleo estratégico, concepção difícil de ser aceita na cultura política brasileira.

Para isso, a questão da independência do órgão regulador é vista tanto como uma das premissas-chave do modelo quanto objeto de controvérsias. Segundo Moreira (como citado em Marques Neto, 2003, p. 29), "o traço essencial de tais organismos é naturalmente a sua autonomia ou independência dos respectivos membros. Não estão organicamente integrados na administração ordinária do Estado, nem estão sujeitos a orientações ou controle governamental quanto à condução da sua atividade".

$\mathrm{Na}$ prática, as agências independentes brasileiras estão vinculadas hierarquicamente (não estão subordinadas) aos respectivos ministérios e têm sido objeto de controle interno e externo. Medidas como estabilidade dos dirigentes, autonomia administrativa, financeira e técnica buscam dotar o modelo brasileiro de agência de maior independência.

Nesse contexto de desestatização e tentativas de reformas gerenciais, é redefinido o papel do Estado, qualificando-o mais como regulador do que como indutor do processo de desenvolvimento do país. Paralelamente - mas não articuladamente - é enfatizada a importância de uma flexibilização da ação pública, propondo-se um conjunto de medidas uniformizadoras inspiradas na Nova Gestão Pública (New Public Management), que visam dar ao administrador público mais autonomia gerencial, numa tentativa de tornar a administração pública mais parecida com a administração de empresas: o chamado movimento de agencificação.

Na prática, conforme Martins (2004) analisa, é possível diferenciar três gerações diferentes no processo de criação das agências reguladoras. A primeira geração, que abrange o período 1995-98, caracteriza-se pela criação das chamadas agências reguladoras de infra-estrutura, como a Agência Nacional de Energia Elétrica (Aneel), Agência Nacional de Telecomunicações (Anatel) e Agência Nacional 
de Petróleo (ANP). A seguir, em 1999/2000, foram criadas a Agência Nacional de Vigilância Sanitária (Anvisa), a Agência Nacional de Saúde Suplementar (ANS) e a Agência Nacional de Água (ANA). Durante o período 2001/2002, foram criadas a Agência Nacional do Cinema (Ancine), a Agência Nacional de Transportes Terrestres (ANTT) e a Agência Nacional de Transportes Aquaviários (Antaq). Embora as agências apresentem finalidades diferentes - como a regulação de monopólios naturais, a correção de falhas de mercado, a presença de externalidades e a solução de problemas de coordenação (Melo, 2002) -, são caracterizadas por um alto grau de isomorfia organizacional.

A reforma regulatória brasileira torna-se mais complexa como consequiência das características do sistema federativo no país. As agências reguladoras multiplicam-se em diferentes unidades da federação, não apenas como resultado da reforma de desestatização que abrange estados e municípios, mas também visando responder às titularidades que a própria Constituição define quanto aos serviços públicos.

\section{Análise do Marco Regulatório no Brasil da Pós-Privatização}

Analisar o marco regulatório no Brasil da pós-privatização não é tarefa trivial. Trata-se de um conjunto complexo de políticas e estruturas institucionais que se tornou atuante na esfera pública num período de tempo relativamente curto.

Como foi ressaltado, a criação das agências reguladoras está estreitamente relacionada com um duplo movimento: o processo de enxugamento do papel do Estado na economia - ou a reforma de desestatização - e o conjunto de instrumentos de reforma administrativa que visavam à flexibilização da gestão pública, ou a Nova Gestão Pública. Essa dupla dimensão materializa-se na sua própria denominação: agência (que representa o conjunto de medidas que visam à flexibilização da gestão pública) e reguladora (que representa o papel do Estado no contexto da pós-privatização).

Embora na prática essas duas dimensões estejam estreitamente imbricadas, neste artigo é feito um esforço de diferenciação, com o argumento de que essa conjunção não decorre de um processo de formulação e articulação estratégica, mas, pelo contrário, representa muito do quadro fragmentado das políticas públicas que caracterizou a gestão pública nos últimos anos (Martins, 2004). O fato é que foi dada prioridade aos objetivos econômicos em detrimento de outras metas da reforma gerencial, relativas à consolidação da governança e da governabilidade do Estado brasileiro. A extinção do Ministério da Administração e Reforma do 
Estado em 1998, a descontinuidade no processo de implementação de conjuntos de projetos contidos no Plano Diretor da Reforma do Aparelho de Estado e o uso de decretos presidenciais, além de outros fatos ilustram bem esse ponto. Enquanto o Programa Nacional de Desestatização ganhava cada vez mais força política no governo e o setor privado avançava em áreas de infra-estrutura como energia e telecomunicações, a reforma gerencial fracassava por falta de apoio governamental, por incapacidade de sobrepor-se ao predomínio do enfoque econômico (Brasil, 2004).

A seguir, são apresentadas algumas reflexões acerca das vulnerabilidades do modelo regulatório e é analisada a política regulatória, com um diagnóstico das medidas de flexibilização da gestão pública, aplicadas ao modelo agência reguladora.

\section{Vulnerabilidade do Modelo Regulatório}

Nos primeiros anos de funcionamento, as agências têm enfrentado sérios problemas relativos ao estabelecimento de um adequado quadro de funcionários, especificamente os técnicos. A Lei das Agências (n 9.986/2000) - que dispõe sobre os quadros de servidores das agências - foi contestada no Supremo Tribunal Federal (STF), com base na Ação Direta de Inconstitucionalidade (Adin) ํo 2310 interposta pelo PC do B e pelo PT, com o argumento de que está em desacordo com a Emenda Constitucional no 19, a qual estabelece que as funções de fiscalização e regulação são atividades típicas do Estado. Uma liminar foi obtida, suspendendo a validade de alguns artigos, o que dificultou a realização de concursos. A solução adotada foi a contratação de quadros temporários, aumentando, assim, o risco de captura do órgão regulador, tornando as agências reféns de altos índices de rotatividade.

Ainda nesses primeiros anos, também foi possível testemunhar vários indícios de vulnerabilidade do modelo regulatório brasileiro, como os casos de boicote financeiro e administrativo por parte de algumas agências estaduais: Arse-MG, Asep-RJ e Agergs-RS (Melo, 2002). No primeiro caso, a agência foi criada pela Lei no 12.999/99, mas não foi implantada pelo governo Itamar Franco. A AsepRJ, criada no governo Marcelo Alencar pela Lei estadual no 2686/97, esteve paralisada nos seus primeiros dois anos de funcionamento, embora o estado do Rio de Janeiro tenha sido pioneiro no processo de desestatização, com a venda da Cerj e da CEG/Riogás. A Asep-RJ permaneceu refém de interferências e indecisões políticas, mesmo nos governos Anthony Garotinho e Rosinha Garotinho. No caso da Agergs, ocorreu contestação judicial em vários níveis da cobrança da taxa de fiscalização que daria autonomia à agência, considerada inconstitucional pelo Executivo estadual. Embora a Suprema Corte tenha garantido a autonomia 
da regulação dos serviços públicos no Brasil, o caso demonstrou a possibilidade de interferência política nos órgãos reguladores estaduais (Peci \& Cavalcanti, 2000).

Outros indícios da vulnerabilidade do regime regulatório brasileiro em nível federal foram revelados durante a crise energética enfrentada em 2001. Com a crise, foram criados diversos órgãos que abalaram seriamente a autonomia e a estabilidade da Aneel, assumindo muitas das suas funções, entre os quais se destaca o Comitê de Gestão da Crise Energética (Melo, 2002). A medida provisória que instituiu esse comitê deu-lhe poderes antes atribuídos ao Ministério de Minas e Energia e à Aneel. Esse exemplo ilustra o elevado risco político que a inadequada prestação de serviços públicos cruciais acarreta para o governo, cujos índices de popularidade diminuíram significativamente durante a crise em exame.

Pacheco (2003) analisa a relação das agências com os três poderes e argumenta que o Executivo demonstrou inconformismo com a perda de poder para os novos órgãos. Todos os exemplos anteriormente citados se referem a esse inconformismo e apontam indícios de relação conflituosa entre o Poder Executivo e esses novos organismos.

No nível estadual, os conflitos entre o Executivo e as agências reguladoras se agravaram por não terem sido consideradas, na reforma de desestatização, as peculiaridades da federação brasileira. Antes dessa reforma, as responsabilidades relativas à propriedade e gestão dos serviços públicos eram compartilhadas nem sempre de maneira uniforme - entre os níveis da federação; por exemplo, no setor elétrico, coexistiam empresas estaduais verticalizadas e empresas federais, como no Rio de Janeiro e em Minas Gerais; enquanto no setor de saneamento, municípios e estados assumiam papéis e responsabilidades diferenciados. Com a desestatização, os estados perderam muito do poder que exerciam direta ou indiretamente através das empresas estatais. Conseqüentemente, alguns governos estaduais encontraram nos organismos reguladores estaduais uma forma indireta de influenciar as políticas públicas relativas aos serviços públicos.

Por outro lado, ainda há muitos problemas de entendimento do modelo, desde a filosofia de concepção até os papéis dos diversos atores. O fator desconhecimento se fez presente até nos primeiros momentos do governo Lula, quando o próprio presidente caracterizou a atuação das agências como uma terceirização do Estado, e o ministro das Telecomunicações Miro Teixeira tentou assumir a negociação direta com as empresas para obter reajustes inferiores (Pacheco, 2003).

A reforma regulatória tem caráter muito abrangente e permanece inacabada. Em vários setores, ainda não foi concluída a fase de transição do modelo anterior 
de auto-regulação concentrado em ministérios e departamentos governamentais para um modelo centrado em agências independentes. Mesmo levando em conta que o modelo agência proliferou na maioria dos setores que antes eram de exclusiva atuação estatal, outros setores ainda permanecem sem marco regulatório definido, como é o caso do setor de saneamento. Em outros, os resultados apresentados foram frustrantes quanto à capacidade de atrair investimento do setor privado, como ocorre no setor elétrico. Ao mesmo tempo, setores como petróleo e energia elétrica adotaram arcabouços regulatórios, mas mantiveram órgãos estatais explorando atividades econômicas (Marques Neto, 2003).

\section{A Política Regulatória}

Para o modelo conceitual de agência independente, a política regulatória assume grande relevância, sendo responsabilidade do chamado núcleo estratégico a definição dos macrobalizamentos da política regulatória a ser implementada pelas agências setoriais.

Tradicionalmente, os objetivos de uma política reguladora são a defesa da concorrência e a defesa do usuário dos serviços públicos. A regulação visa manter o chamado equilíbrio econômico-financeiro, sem permitir que os consumidores sejam lesados ou mesmo negligenciados pelos prestadores dos serviços. Embora muitas vezes esses objetivos sejam apresentados como não conflitantes entre si, sob o argumento de que a defesa da concorrência cria condições favoráveis ao usuário do serviço público, na prática nem sempre isso ocorre. Uma política forte de defesa da concorrência não abre espaço para o uso de subsídios a tarifas voltadas para as camadas desfavorecidas da população. A hierarquização desses objetivos é prática comum em países como Reino Unido, sendo considerada uma importante definição política.

Contudo, um dos principais pontos de estrangulamento do modelo regulatório brasileiro está relacionado com a ausência de uma política regulatória. Esse problema pode ser visto como conseqüência do processo de criação das agências (caracterizado pela incoerência e falta de consenso político) e do mimetismo das estratégias formais (ou seja, relativas apenas à discussão da forma organizacional agência independente) adotadas em nível internacional, sem que tenha havido uma discussão sobre as premissas, a relevância e as funções do modelo.

Como resultado, existe um conjunto de entidades reconhecidas como agências reguladoras, mas com objetivos e funções muito diferenciados. Basta comparar agências como a Anatel, a Aneel e a ANTT com a Ancine, por exemplo. Isso significa que na ausência de macrobalizamentos da política regulatória, o modelo 
agência começa a proliferar em vários setores, sem que, no entanto, seja justificado como uma estratégia formal.

Uma das principais falhas da política regulatória está no processo de formulação. Paradoxalmente, as políticas regulatórias no Brasil não foram caracterizadas pela falta das estruturas responsáveis pela formulação dessas políticas. De fato, a criação dessas estruturas - na sua grande maioria conselhos - foi prevista em lei. Existem órgãos de formulação de política, assim como de planejamento em vários setores de infra-estrutura como o de energia (Conselho Nacional de Política Energética) e o de transportes (Conselho Nacional de Integração de Políticas de Transporte). No caso do setor elétrico, embora se argumente que cabe ao Conselho Nacional de Política Energética o papel de planejamento da expansão, é importante lembrar que esse planejamento assumiu apenas caráter indicativo a partir da nova reestruturação do setor (Peci, 2001). Destaca-se também a Câmara de Políticas de Infra-estrutura, do Conselho de Governo, criada em 1995 com o objetivo de formular as políticas públicas e diretrizes para infra-estrutura, além de coordenar sua implementação, mas cuja atuação pouco foi sentida na prática.

A ausência de uma política que orientasse a atuação das agências reguladoras e o fato de que essa lacuna vinha sendo ocupada, de forma anômala, pelas próprias agências, já tinham sido constados pelo Tribunal de Contas da União (TCU) em auditorias na Aneel e na ANP. Isso evidenciou a necessidade de atuação efetiva do Conselho Nacional de Política Energética (CNPE), instituído pela Lei no 9.478/97 e efetivamente implantado em novembro de 2002. O papel que o TCU desempenhou nesse período de implementação das agências reguladoras é relevante, embora tenha passado despercebido, abrindo espaço para uma das críticas mais comuns às agências reguladoras: a ausência de controle externo.

O problema é que a reforma foi baseada numa concepção que alienou o processo de formulação de políticas da sua implementação. Sendo o primeiro processo responsabilidade do núcleo estratégico do governo; na prática, as estruturas criadas para desempenhar o papel de formulador pouco ou nada fizeram, por falta de quadros, de orientação, por não terem recebido prioridade do ponto de vista político, como também por falta de capacidade decisória, entre outros motivos. Certamente, o problema está no esvaziamento dos papéis desses colegiados e na falta de credibilidade desses órgãos de formulação política e planejamento, no contexto da ideologia dominante do Estado mínimo.

O que parece ter acontecido é uma falha de processo, e não de estruturas previstas para tais fins. Conseqüentemente, as estruturas criadas para implementar 
as políticas públicas, como no caso das agências reguladoras, começaram a concentrar superpoderes, amarrados a um complexo marco jurídico. Na falta de definição, pelo próprio governo, dos objetivos da política regulatória, as agências definiram suas próprias políticas regulatórias setoriais, levando, assim, a uma concorrência de poderes com os ministérios. Por sua vez, o novo governo critica as agências por terem assumido essa função do Poder Executivo. A Agência Nacional de Energia Elétrica (Aneel), a Agência Nacional do Petróleo (ANP) e a Agência Nacional de Telecomunicações (Anatel) estariam criando políticas para as áreas de infra-estrutura, papel exclusivo dos ministérios de Minas e Energia e de Comunicações, respectivamente.

\section{Regulação e Flexibilização da Gestão Pública}

Já se destacou que a concepção das agências reguladoras tem raízes no Plano Diretor da Reforma do Aparelho de Estado. No entanto, esse plano não detalhou uma proposta institucional para as agências reguladoras (Pacheco, 2003). Enquanto para Martins (2004) essa posição refletiu o quadro fragmentado de políticas públicas que caracterizou a era FHC, para Pacheco (2003, p. 2-3):

é compreensível a falta de precisão com que o tema da regulação foi tratado no Plano Diretor: no início de 1995, época de elaboração do Plano Diretor, o debate político-institucional sobre regulação não havia ainda sido iniciado; o Congresso discutia as primeiras emendas constitucionais que quebravam monopólios estatais.

Esses dois pontos de vista não são necessariamente contraditórios, uma vez que se referem a diferentes estágios de maturação do debate acerca da reforma regulatória. Pacheco (2003) identifica, adequadamente, que existe uma relação intrínseca entre aspectos político-institucionais relativos ao novo papel do Estado e as formas que os novos organismos reguladores devem ou não assumir. Martins (2004) chama atenção pela possibilidade de fragmentação dessa relação durante o processo de inclusão na agenda, formulação e implementação de políticas públicas. Essa fragmentação torna mais compreensível o descompasso, observável na prática, na proliferação do modelo agência nos mais diversos setores, cuja revisão conceitual nem sequer tinha sido iniciada no Congresso Nacional.

Entretanto, o conjunto de medidas que visam à flexibilização da gestão pública, denominado aqui de Nova Gestão Pública, tinha por principal objetivo enfatizar questões como autonomia, independência e flexibilidade dos órgãos públicos, conceitos como responsabilização e busca de resultados, além de um conjunto de medidas que visavam aproximar a administração pública da administração privada. 
Embora as estratégias recomendadas nesse documento não tenham sido implementadas na sua totalidade, desempenharam um papel importante em termos de difusão discursiva (Foucault, 1972) dos principais conceitos da Nova Gestão Pública. As agências reguladoras incluíram-se nessa onda flexibilizadora, manifestada claramente no grau de isomorfismo organizacional que apresentam. A autonomia, a estabilidade e as formas de escolha dos dirigentes, a figura jurídica de autarquia especial sem subordinação hierárquica, a independência financeira, administrativa e gerencial, as medidas de publicidade, comunicação e contato com os usuários, a presença dos colegiados e outras medidas similares estão presentes na maioria das agências criadas.

A presença do contrato de gestão em algumas agências também se insere no quadro das medidas de flexibilização gerencial (Melo, 2002). Nessa dimensão também as agências reguladoras têm sofrido com as descontinuidades do processo de formulação e implementação da Política de Gestão Pública, inicialmente expressa nas idéias do Plano Diretor e, a seguir, influenciada pela concepção do Plano Plurianual Avança Brasil 2000-2003. No caso da Aneel, o primeiro contrato de gestão foi assinado em 2-3-1998, teve vigência até 31-12-2000 e foi objeto de auditorias pela Secretaria Federal de Controle durante os exercícios 1998 e 1999, quando foi verificado um desempenho satisfatório. Na auditoria realizada na Aneel, exercício 2000, pelo TCU (Brasil, 2001), os auditores constataram que as metas da agência, estipuladas no contrato de gestão, foram agrupadas em dois grandes programas contemplados no PPA, fazendo com que o contrato assumisse um caráter formal, uma função redundante em relação a outros instrumentos de planejamento e orçamento. A manutenção do contrato de concessão foi considerada redundante e sobreposta aos controles já realizados por meio do PPA.

É importante observar que os projetos de reforma que tramitam no Congresso Nacional discutem apenas os aspectos relativos à forma e estrutura das agências reguladoras, sem debater profundamente o novo papel do Estado, definido como regulador. De autoria do deputado Mário Assad Júnior (PL-MG), o Projeto de Lei no 465/2003 aumenta o prazo da quarentena dos conselheiros e diretores das agências para um ano. A deputada Telma de Souza (PT-SP) quer restringir a autonomia das agências e dar poderes ao presidente da República para exonerar conselheiros e diretores (Projeto de Lei no 413/2003). Hoje, só se pode exonerar um dirigente de agência se ele for condenado por improbidade administrativa. Além disso, existem vários requerimentos na Câmara dos Deputados convidando diretores das agências para prestar esclarecimentos sobre suas áreas (Investnews, 2003). 


\section{Discussão da Reforma Regulatória: Revisitando o Modelo Conceitual de Kleber Nascimento}

Para aprofundar a análise da reforma regulatória e conceituá-la à luz de outros esforços reformadores empreendidos no Brasil, foi revisitado o modelo teórico proposto por Kleber Nascimento (1967). Buscou-se observar até que ponto a maneira como vem sendo implementada a reforma regulatória brasileira se distancia das características apontadas por Nascimento nas reformas anteriores.

O autor abstrai um modelo teórico da estratégia de mudança que tem presidido a experiência reformista brasileira. $\mathrm{O}$ modelo não tem como único objetivo analisar as grandes reformas de estrutura. Pretende também examinar quaisquer tentativas de mudanças consideráveis na administração pública, especialmente as que dependam de aprovação legislativa por alterarem critérios básicos de operação, direitos e relações de autoridade (Nascimento, 1967, p. 22-23), podendo ser adaptado para a análise da reforma regulatória.

Após detalhado estudo do conjunto de reformas implementadas até 1967, Nascimento (1967, p. 19) configura um modelo conceitual, em que qualifica os principais componentes.

a) Componente operativo ou ação

. foco de ação: elementos formais;

. estilo de influência: impositiva;

· dinâmica de poder: insulativa.

b) Componente substantivo ou conteúdo

. escopo de mudança: globalista-imediatista;

. orientação diagnóstica: cognitivismo.

c) Componente ideológico ou valor

. estratégia e pré-requisitos comportamentais;

. estratégia e orientação processualística.

Todas essas dimensões são analisadas nesse estudo, com exceção da orientação diagnóstica, de difícil análise por causa do quadro fragmentado de políticas públicas anteriormente destacado. 
É possível perceber, em termos de componentes operativos da reforma regulatória analisada, um foco de ação em elementos formais do sistema. "O rationale destas reformas funda-se na premissa de que maior eficiência pode ser obtida, se os arranjos estruturais da burocracia facilitarem, ao invés de obstruírem, o processo administrativo" (Nascimento, 1967, p. 21). As agências reguladoras - novos arranjos burocráticos, caracterizados pela maior autonomia e flexibilidade - são concebidas para assumir o papel do Estado no contexto da pós-privatização.

Por outro lado, o continuísmo dos esforços de reforma também é percebido no estilo de influenciação impositiva, em vez de um processo alternativo de internalização. "O primeiro caracteriza-se como predominantemente mandatório, cujas soluções são apresentadas em forma final, perfeitas e acabadas, deixandose pouca ou nenhuma flexibilidade para ações alternativas, à luz de condições inesperadas" (Nascimento, 1967, p. 21). Esse caráter impositivo esteve presente em dois momentos importantes: na concepção do modelo agência, no âmbito do antigo Mare, e na implementação do modelo, a partir da predominância da ótica economicista, destacando aqui o papel do BNDES, órgão gestor do Programa Nacional de Desestatização.

O modelo elaborado por Nascimento ainda parece válido para analisar a dinâmica de poder da reforma, qualificada pelo autor como insulativa:

Noutros termos, o grupo de reforma não se amplia numericamente à medida que a reforma se desencadeia, mas se insula, se isola dos demais agentes do sistema. Deste modo, ao invés de converter para o processo reformista, gradualmente, camadas cada vez maiores da estrutura de liderança do serviço público, o grupo de reforma age como se em defesa da "sua" reforma, gerando a indiferença, quando não o antagonismo, das chefias e assessorias de todos os níveis (Nascimento, 1967, p. 25).

No caso da reforma regulatória, essa dinâmica insulativa é reforçada, uma vez que o modelo agência reguladora premia uma relativa autonomia da agência em relação aos pólos de interesse: governo, concessionárias e usuário do serviço público. Como se destaca no texto, um dos resultados dessa insulação é o inconformismo do Poder Executivo perante os novos órgãos. Edson Nunes (2001) analisa essa dinâmica de poder desencadeada com a reforma regulatória, qualificando a existência de agências reguladoras como um "Estado dentro do Estado" (Nunes, 2001, p. 3).

Com relação ao componente substantivo, ou seja, ao conteúdo da reforma, Nascimento novamente oferece uma qualificação que permanece válida para a análise da reforma regulatória. Classificando o escopo da mudança como 
globalista-imediatista, ele se refere a uma dupla dimensão: abrangência - uma reforma pode ser parcial ou global; e, tempo - uma reforma pode ser imediatista, de médio ou longo prazo. "A experiência brasileira", continua o autor, "tem-se caracterizado por um globalismo-imediatista, em que se pretende fazer "tudo de uma vez".

O globalismo da reforma regulatória pode ser identificado na relação direta que se estabelece entre as novas entidades regulatórias e o novo papel do Estado, classificando este como Estado regulador e reduzindo todo o foco da reforma do Estado à instituição de agências. Igualando a função das agências reguladoras com o novo papel do Estado - retórica essa construída num breve período de tempo -, abre-se espaço para que as agências assumam, na prática, superpoderes, em detrimento de outras entidades da administração pública direta e indireta, como ministérios, colegiados de formulação de políticas e planejamento. Basta dar uma olhada na missão das agências - como no caso da Anatel -, para verificar as responsabilidades que se transferem para os novos órgãos. Aumenta o grau desse globalismo, se considerada a abrangência da reforma em termos setoriais e federativos. O imediatismo da reforma - num breve período de tempo, agências reguladoras proliferam nos mais diversos setores, como nos de energia e cinema - agrava os conflitos e as vulnerabilidades regulatórias analisadas neste artigo.

Por fim, em termos de componente ideológico ou valorativo das reformas, Nascimento (1967) identifica que "a estratégia prevalecente na experiência reformista brasileira é baseada em pré-requisitos comportamentais, e a segunda, a de que a estratégia pressupõe um condicionamento dos fins pelos meios - uma orientação processualística" (1967, p. 35). Caso a reforma esteja baseada em pré-requisitos - denominados neste estudo de premissas - estes vão influenciar os rumos da mudança planejada que se pretende com a reforma.

Nascimento (1967) identifica pré-requisitos comportamentais burocráticos como predominantes nas reformas brasileiras até 1967. Quando comparados com a dimensão ideológica da atual reforma regulatória, é possível observar que, embora os pré-requisitos comportamentais existam, estes assumem nova qualificação pós-burocrática, o que se denomina no Plano Diretor da Reforma do Aparelho de Estado de administração gerencial. Os representantes dessa corrente se reportam à Nova Gestão Pública para criticar as características comportamentais da administração pública burocrática. Para isso é proposto como alternativa a administração pública gerencial, caracterizada fundamentalmente pela eficiência dos serviços prestados a milhares, senão milhões de cidadãos. Nesse sentido, princípios como flexibilidade, foco no cliente e orientação para resultados permeiam essa nova visão da administração pública. 
Outros pré-requisitos comportamentais do modelo podem ser encontrados no desejável perfil técnico da agência. Embora, teoricamente, os modelos regulatórios sejam caracterizados pela diferenciação entre o poder concedente e o ente regulador, cabendo ao primeiro definições estratégicas (políticas) e ao último, definições técnicas, na prática esses dois papéis vêm se confundindo. O envolvimento das agências no processo de licitação e outorga contribui ainda mais para isso. $\mathrm{O}$ fato é que diferenciar o técnico do estratégico pode ser apenas didaticamente ilustrativo, mas praticamente complexo, para não dizer impossível. A estratégia visada foi baseada em pré-requisitos comportamentais atípicos na burocracia brasileira, ao contrário da burocracia americana que serviu de inspiração ao modelo brasileiro, permeada, desde longos anos, pelos valores da cientificidade e tecnicidade, sem levar em consideração outros pontos importantes de diferença entre os dois contextos, relativos à dimensão da democracia e controle social.

Por fim, outro pré-requisito comportamental identificado na reforma regulatória tem a ver com a existência do controle social. Como já visto, partiu-se da premissa de que o usuário do serviço público vai participar ativamente do modelo, enquanto, na prática, foi observado que, nos primeiros anos de funcionamento das agências, era alto o grau de desconhecimento sobre estas. Outra crítica refere-se ao fato de que o papel do cidadão se reduz ao conceito do consumidor/usuário do serviço público.

Transformado apenas em consumidor, o cidadão eleitor carece de meios para inquirir e interpelar o (mini, sub, supra) Estado que governará a água que bebe, a eletricidade que consome, o telefone que usa, o rádio que ouve e a televisão que vê, o ensino que obtém, o transporte que utiliza, o remédio que dá a seu filho (Nunes, 2001, p. 4).

Por outro lado, identifica Nascimento (1967), a estratégia de orientação processualística - isto é, o condicionamento do alcance dos fins pela eficiência dos meios - marcou profundamente a concepção administrativa dos reformadores. Com isso, o autor entende que dentre as possíveis conseqüências dessa orientação pode-se observar uma superconcentração do esforço reformista nas atividades-meio, em detrimento dos objetivos que, em verdade, justificam a existência do serviço público. "Ocorreu exatamente the triumph of technique over purpose, ou seja, o predomínio de uma orientação processualística sobre uma orientação finalística" (Nascimento, 1967, p. 39). No caso da reforma regulatória, tal posicionamento é exemplificado pela quase inexistência do debate e do consenso político sobre o papel do Estado. A rapidez e a abrangência das reformas de desestatização induziu a profusão do discurso que classificou o novo papel do Estado como regulador, ao passo 
que os debates mais calorosos acompanhavam aspectos formalísticos dos novos entes regulatórios, sem, no entanto, discutir sua verdadeira relevância no novo contexto da ação estatal. Contudo, os elementos formais da reforma não chegam "a materializar transformações, perdendo-se num vácuo de indiferença ou numa atmosfera de antagonismo" (Nascimento, 1967, p. 39). O Quadro 1 resume a análise da reforma regulatória, à luz do modelo de Kleber Nascimento:

\section{Quadro 1: Análise da Reforma Regulatória à Luz do Modelo de Kleber Nascimento}

\begin{tabular}{|c|c|c|c|}
\hline $\begin{array}{l}\text { Componentes } \\
\text { de análise }\end{array}$ & Qualificação & Contextualização & Vulnerabilidades \\
\hline \multirow[t]{5}{*}{$\begin{array}{l}\text { Componente } \\
\text { operativo: }\end{array}$} & \multirow[t]{2}{*}{$\begin{array}{l}\text { Foco de ação: } \\
\text { elementos formais }\end{array}$} & $\begin{array}{l}\text { Novos arranjos } \\
\text { burocráticos }\end{array}$ & $\begin{array}{l}\text { Aspectos formais do modelo } \\
\text { ainda sob discussão }\end{array}$ \\
\hline & & & $\begin{array}{l}\text { Ausência de políticas } \\
\text { regulatórias (embora existam } \\
\text { estruturas previstas para esse } \\
\text { fim) }\end{array}$ \\
\hline & \multirow[t]{2}{*}{$\begin{array}{l}\text { Estilo de influência: } \\
\text { impositivo }\end{array}$} & $\begin{array}{l}\text { Concepção unilateral } \\
\text { pelo Mare }\end{array}$ & $\begin{array}{l}\text { Conflito Poder Executivo / } \\
\text { agências reguladoras }\end{array}$ \\
\hline & & $\begin{array}{l}\text { Implementação viés } \\
\text { economicista }\end{array}$ & \\
\hline & $\begin{array}{l}\text { Dinâmica do poder: } \\
\text { insulativa }\end{array}$ & $\begin{array}{l}\text { Premissa da autonomia } \\
\text { reforça o poder } \\
\text { insulativo }\end{array}$ & O quarto poder \\
\hline \multirow[t]{2}{*}{$\begin{array}{l}\text { Componente } \\
\text { substantivo: }\end{array}$} & \multirow[t]{2}{*}{$\begin{array}{l}\text { Escopo de mudança: } \\
\text { globalista-imediatista }\end{array}$} & $\begin{array}{l}\text { Abrangência setorial e } \\
\text { federativa }\end{array}$ & $\begin{array}{l}\text { Alto grau de desconhecimento } \\
\text { do modelo }\end{array}$ \\
\hline & & $\begin{array}{l}\text { Agência - novo papel } \\
\text { do Estado } \\
\text { Tempo de reforma }\end{array}$ & $\begin{array}{l}\text { Proliferação do modelo } \\
\text { agência em setores onde tal } \\
\text { atuação não encontra } \\
\text { justificação teórica - cinema }\end{array}$ \\
\hline \multirow[t]{4}{*}{$\begin{array}{l}\text { Componente } \\
\text { ideológico: }\end{array}$} & \multirow{3}{*}{$\begin{array}{l}\text { Estratégia e pré- } \\
\text { requisitos: } \\
\text { comportamentais }\end{array}$} & Administração gerencial & $\begin{array}{l}\text { Confusão regulação / } \\
\text { flexibilização da gestão pública }\end{array}$ \\
\hline & & $\begin{array}{l}\text { Perfil desejável para } \\
\text { agência - técnico }\end{array}$ & Conflito política / técnica \\
\hline & & Controle social & $\begin{array}{l}\text { Grau mínimo de controle social } \\
\text { observado na prática }\end{array}$ \\
\hline & $\begin{array}{l}\text { Estratégia e orientação: } \\
\text { processualística }\end{array}$ & $\begin{array}{l}\text { Predomina o foco nos } \\
\text { aspectos formais do } \\
\text { modelo agência } \\
\text { independente }\end{array}$ & $\begin{array}{l}\text { Discute-se o modelo formal em } \\
\text { detrimento do debate } \\
\text { democrático acerca do novo } \\
\text { papel do Estado }\end{array}$ \\
\hline
\end{tabular}

Fonte: elaboração própria. 


\section{Reflexões Finais}

Olhar o marco regulatório brasileiro de uma perspectiva histórica pode ajudar a compreender melhor a persistência de algumas características presentes nos esforços reformistas da administração pública brasileira. Essas características influenciam o alto grau de formalismo - incongruência entre o prescrito e o observado - traço institucionalizado em sociedades caracterizadas por Riggs (1964) como sociedades prismáticas. Esse formalismo, potenciado pelo foco nos aspectos formalísticos do modelo agência independente, está presente no distanciamento observado no processo de formulação e implementação do marco regulatório, assim como nos conflitos que nascem da dicotomia política/técnica. Entretanto, como se destaca neste estudo, esse distanciamento é favorecido pelas próprias premissas teóricas em que está baseado o modelo agência independente.

A dinâmica insulativa do poder, reforçada pela premissa da autonomia do modelo regulatório, influencia a relação conflituosa e o grau de inconformismo do Executivo perante a criação dos novos entes reguladores, caracterizados por Nunes (2001) como "quarto poder". Esse fator, junto ao escopo globalista-imediatista - típico das reformas da administração pública brasileira -, contribuiu para que essa relação conflituosa se estendesse para outros níveis da federação, onde o modelo agência independente estava sendo adotado, enquanto esse mesmo modelo proliferava, sem consistentes justificativas práticas e teóricas, em setores como cinema.

Talvez a maior mudança apresentada pela reforma regulatória esteja nos prérequisitos comportamentais em que esta se baseia. Foi ressaltado aqui que a administração gerencial se apresenta como nova postura pós-burocrática. No entanto, as medidas de flexibilização presentes nas agências levaram, de forma inesperada, à confusão conceitual que iguala o modelo mais flexível presente nas agências com a reforma regulatória. Esta é uma das principais conclusões do artigo, que talvez mereça mais reflexão.

O debate sobre regulação está restrito aos aspectos formais, isto é, relativos à forma e estrutura de agências reguladoras, sem debater questões importantes como o próprio papel do Estado. Esses são os exemplos apresentados na conclusão deste artigo, visando argumentar que, enquanto o modelo agência avança nos mais diversos setores e níveis da federação e se torna objeto de críticas e/ou declarações de amor calorosas, pouco se discute acerca do novo papel que o Estado brasileiro vem assumindo, no discurso e na prática: o papel regulatório. Afinal: 
Não existe regulação neutra. Nem regulação inocente. Nem toda regulação é contra o regulado. Muitos regulados abençoarão e, neste sentido, buscarão normas regulatórias que os protejam da competição, que lhes diminuam custos, que criem barreira de entradas à competição, que os mantenham no mercado, que os protejam de demandas do público. Nem toda regulação, portanto, é a favor do público. Nem toda regulação é a favor do regulado. O mercado regulatório é um selvagem campo de lutas de interesses (Nunes, 2001, p. 2-3).

Num brevíssimo período de tempo, o Estado brasileiro deixou de ser um grande produtor, controlador e gestor de serviços públicos e começou a assumir um papel importante na área de regulação. Discutir esse novo papel é mais um ponto de controvérsia, uma vez que diferentes visões ideológicas se farão presentes. A regulação é uma forma de intervenção do Estado, embora indireta. Os (neo)liberais consideram a regulação como mais uma forma de intervenção do Estado, não apenas na economia, mas na vida dos cidadãos, enquanto os desenvolvimentistas argumentam que é preciso ter mais ação estatal de forma direta, para diminuir as desigualdades sociais. Para um autor de formação marxista, a política é um reflexo da ordem econômica. Conseqüentemente, seria absurda a hipótese de controle do poder econômico pelo Estado (Wilson, 1980).

Reconhecendo que a controvérsia entre neoliberais e desenvolvimentistas, conservadores e marxistas etc. sobre a forma e os meios de intervenção do Estado na vida econômica e política parece nunca chegar ao fim. É natural e democrático que assim seja. Este estudo chama atenção para o argumento de Polanyi (1980) de que o laisses-faire é uma situação ideal, mas difícil de ser observada na prática. $\mathrm{O}$ autor, a partir de uma perspectiva histórica, mostra que a intervenção do Estado é um movimento natural de autoproteção da sociedade dos efeitos nocivos do mercado, observável todas as vezes que o subsistema econômico tenta se sobrepor ao social.

Paralelamente, a proliferação do modelo agência pode ser vista como expressão de certa atratividade que este exerce, devido, em parte, às medidas de flexibilização da gestão pública que incorpora. Essas medidas continuam a ser vistas como instrumentos desejáveis e necessários para várias organizações do setor público, mas elas não podem ser reduzidas apenas ao modelo agência. Uma associação errada está sendo feita, aquela entre regulação e flexibilização da ação pública. As agências reguladoras não podem ser consideradas como as únicas formas de intervenção e/ou boa gestão. Corre-se o risco de cair no mimetismo em detrimento da reflexão e dos espaços de negociação de alternativas inovadoras de gestão pública.

Artigo recebido em 29.07.2004. Aprovado em 23.03.2005. 


\section{ReferênCias Bibliográficas}

Abranches, S. (1999).

Privatização, mudança estrutural e regulação. In Fórum Nacional O Day After da Privatização da InfraEstrutura. Rio de Janeiro, RJ, Brasil.

Castor, B. V. J. (2000).

O Brasil não é para amadores. Estado, Governo e burocracia na terra do jeitinho. Curitiba: Ebel/IBQPPR.

Costa, F. L., \&

Peci, A. (1999, maio/junho).

Desestatização como estratégia da reforma do estado. Revista de Administração Pública, 33(3), 191205.

Fachin, R. C. (1998).

Reforma do Estado e agências de regulação: o caso do Rio Grande do Sul. In Seminário Internacional sobre Reestruturação e Reforma do Estado: Brasil e América Latina no Processo de Globalização, São Paulo, SP, Brasil.

Fadul, E. M. C. (1998).

Reforma do Estado e serviços públicos: transformação de um modelo ou adaptação à uma nova ordem social? In Seminário Internacional sobre Reestruturação e Reforma do Estado: Brasil e América Latina no Processo de Globalização. São Paulo, SP, Brasil.

Fischer, T.,

Teixeira, E., \&

Heber, F. (1998, maio/junho).

Estratégias de gestão e reconfiguração organizacional: os setores de energia elétrica e telecomunicações. Revista de Administração Pública, 32(3), 9-28.

Foucault, M. (1972).

A arqueologia do saber. Lisboa: Vozes.

InvestNews (2003).

Lula: 100 dias de governo. Relatório. São Paulo. Recuperado em 10 março, 2004, de http//:www.investnews.com.br.

Marques Neto, F. A. (2003).

Agências reguladoras: instrumentos de fortalecimento do Estado. São Paulo: Abar.

Martins, H. F. (2004).

Reforma do Estado na era FHC: diversidade ou fragmentação da agenda de políticas de gestão pública. Tese de Doutorado. Escola Brasileira de Administração Pública e de Empresas, Fundação Getulio Vargas, Rio de Janeiro.

Melo, M. A. (2002).

As agências reguladoras: gênese, desenho institucional e governança. In F. L. Abrucio, \& M. R. Loureiro (Orgs.). O Estado numa era de reformas: os anos FHC. Coleção Gestão Pública. Brasília, DF: ENAP.

Ministério de Planejamento.

Secretaria de Gestão. (2004). Gestão pública para um Brasil de todos: um plano de gestão do Governo Lula. Brasília, DF. Recuperado em 22 maio, 2005, de http/: www.planejamento.gov.br. 
Nascimento, K. (1967, janeiro/junho). Reflexões sobre a estratégia de reforma administrativa: a experiência federal brasileira. Revista de Administração Pública, 1(1), 11-50.

Nunes, E. (2001).

$\mathrm{O}$ quarto poder: gênese, contexto e controle das agências regulatórias. In Seminário Internacional sobre Agências Reguladoras de Serviços Públicos, Brasília, DF, Brasil.

Pacheco, R. S. (2003).

Agências reguladoras no Brasil: Ulisses e as sereias ou Narciso e Eco? Anais do Congresso Internacional del Clad sobre la Reforma del Estado e de la Administración Pública, Panamá, Panamá, 8.

Peci, A. (2001).

O setor elétrico brasileiro: uma rede em construção? Anais do Encontro Nacional de Pós-Graduação em Administração, Campinas, SP, 25.

Peci, A. (2002).

Modelos regulatórios na área de transportes: a experiência americana. Anais do Congresso Internacional del Clad sobre la Reforma del Estado e de la Administración Pública, Buenos Aires, Argentina, 7.
Peci, A., \&

Cavalcanti, B. (2000, setembro/outubro). Reflexões sobre a autonomia do órgão regulador: análise das agências reguladoras estaduais. Revista de Administração Pública, 34(5), 99-119.

Pires, J. C. L. (1999, Dezembro).

Capacity, efficiency and contemporary regulatory approaches In: The Brazilian energy sector: the experiences of Aneel and ANP. Ensaios BNDES, Rio de Janeiro.

Polanyi, K. (1980).

The great transformation. The political e economical origins of our time. Londres: Paperback.

Riggs, F. (1964).

Administration in developing countries: the theory of prismatic society. Boston: Hougton Hifflin.

Tribunal de Contas da União (2001).

Relatório Auditoria (TC-005.793/ 2002-7). Brasília, DF, Brasil.

Wahrlich, B. (1984, janeiro/março).

A reforma administrativa no Brasil: experiência anterior, situação atual e perspectivas - uma apreciação geral. Revista de Administração Pública, 18(1), 49-59.

Wilson, J. Q. (1980).

The politics of regulation. New York: Basic Books. 